\title{
Determination of the optimal transport system for Helicobacter pylori cultures
}

\author{
H. X. XIA, C. T. KEANE and C. A. O'MORAIN* \\ Department of Clinical Microbiology, St James's Hospital and * Department of Gastroenterology, Meath/Adelaide \\ Hospitals, Trinity College, Dublin, Ireland
}

\begin{abstract}
Summary. A range of solid and liquid media was evaluated for the ability to maintain survival of Helicobacter pylori strains under different conditions. Chocolate agar slopes maintained survival of most strains for longer than 3 days, some strains surviving for up to 9 days, despite a decreased number of viable cells. Temperature and atmosphere did not significantly influence the performance of these slopes. The BBL Campy Pouch system also achieved a considerable recovery rate of $H$. pylori after storage for 3 days at the same range of temperatures. Brain-heart infusion broth with horse serum was superior among the liquid media tested, maintaining the viability of $H$. pylori for $c .3$ days at temperatures ranging from $-4^{\circ} \mathrm{C}$ to $21^{\circ} \mathrm{C}$. Chocolate agar slopes are recommended as suitable for transport of $H$. pylori strains.
\end{abstract}

\section{Introduction}

Since the first successful isolation of Helicobacter pylori from gastric mucosa in $1983,{ }^{1}$ techniques and media for isolating, subculturing and storing this organism have been well established. ${ }^{2-5}$ Methods for growing $H$. pylori in various liquid media have also been evaluated. ${ }^{3,6-8} \mathrm{H}$. pylori is a fastidious, micro-aerophilic species that can survive at temperatures from $4^{\circ} \mathrm{C}$ to room temperature $\left(21^{\circ} \mathrm{C}\right)$ for only $5-48 \mathrm{~h}$ in most conventional media such as nutrient broth, ${ }^{9}$ thioglycollate broth, ${ }^{10}$ Brucella broth, normal saline, ${ }^{11}$ hypertonic glucose ${ }^{2}$ and Stuart's transport medium. ${ }^{12}$ Therefore, transportation of this organism is difficult and recovery from freeze-dried cultures is poor. ${ }^{13}$

The aim of this study was to determine the survival time of $H$. pylori cultures in a number of potential transport media, and particularly on chocolate agar slopes, at different temperatures, with and without the addition of $\mathrm{CO}_{2}$ to the atmosphere.

\section{Materials and methods}

\section{Bacterial strains}

All $H$. pylori strains in the present study were isolated from antral biopsy specimens, and were identified by their typical morphology with Gram's stain, rapid urease reaction and positive oxidase and catalase tests. Sixteen strains were used to evaluate solid media, four for atmospheric requirements for chocolate agar slopes and 16 for BBL Campy Pouch evaluation. Twelve strains were used to study liquid media.

\section{Evaluation of solid media}

Chocolate agar plates (CAP) and chocolate agar slopes (CAS) were prepared from Columbia Agar Base (Lab M, Bury) with heated horse blood 7\%. Three-day-old cultures of 16 strains from CAP were subcultured on to CAP and CAS. These were incubated at $37^{\circ} \mathrm{C}$ for 3 days and were then held at room temperature $\left(21^{\circ} \mathrm{C}\right)$ and external environmental temperature (i.e., outside at winter temperatures ranging from $-4^{\circ} \mathrm{C}$ to $14^{\circ} \mathrm{C}$ ). Subcultures to CAP were carried out at $3 \mathrm{~h}$ and 1, 2, 3, 5, 7, 9 and 11 days to check the viability of the strains.

To evaluate the capability of BBL Campy Pouches (Cam.P; BBL Microbiology Systems, Cockeysville, $\mathrm{MD}$, USA) to maintain viability of $H$. pylori, the strains were inoculated on to CAP and incubated at $37^{\circ} \mathrm{C}$ for 3 days. The plates were sealed in the Campy Pouches according to the manufacturer's instructions and held at the same range of temperatures. Subcultures were performed at the same time intervals as before.

All subcultures were placed in Gaspak jars (Gaspak System, BBL), flushed with $\mathrm{CO}_{2}$, and incubated at $37^{\circ} \mathrm{C}$ for 5-7 days. Growth of colonies was scored according to density as,,++++++ and negative $(-)$. 


\section{Determination of transport conditions for CAS}

As CAS gave the best results in the previous experiments, it was decided to determine the effect of atmospheric conditions on their performance. Four $H$. pylori strains (IRL911200, IRL911201, IRL911206 and IRL911207) were each subcultured on six CAS and incubated for 4 days. Each set of six was divided into three pairs, $\mathrm{CO}_{2}$ was added to one of each pair and the pairs were then stored at $37^{\circ} \mathrm{C}$, room temperature and external environmental temperature as before. The slopes were subcultured at $3 \mathrm{~h}, 2,4,6,8$ and 10 days, as described previously.

\section{Evaluation of liquid media}

The three liquid media tested were Nutrient Broth No. 2 (NB, Oxoid), Brain Heart Infusion Broth (Oxoid) with horse serum (Oxoid) $10 \%$ (BHIS), Tryptone Soya Broth (Oxoid) with glycerol (BDH, Laboratory Supplies, Poole) $30 \%$ and horse serum $10 \%$ (TSGS). These liquid media were assessed as transport media. Because it is difficult to grow the organism in liquid culture, 3-day-old subcultures of 12 strains from CAP were suspended in $5 \mathrm{ml}$ of the broths, yielding a density of $c .10^{6} \mathrm{cfu} / \mathrm{ml}$. These suspensions were placed directly at the room temperature and the external environmental temperature. Subcultures were performed at $3 \mathrm{~h}$ and $1,2,3,5,7,9$ and 11 days, as previously described.

\section{Results}

\section{Evaluation of solid media}

The survival time of $H$. pylori on CAS was much longer than on CAP. However, CAP in the BBL Campy Pouch system gave a similar recovery rate to CAS within 3 days of storage, but could not maintain viable $H$. pylori for 9 days (fig. 1 ).

\section{Determination of transport conditions for CAS}

All four strains survived on CAS for at least 2 days at different temperatures and two strains survived for

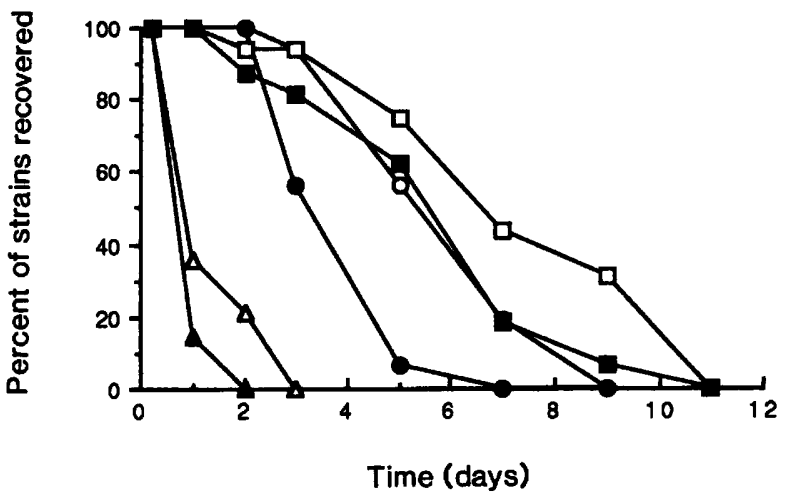

Fig. 1. Recovery rates of $H$. pylori after storage in solid media at different temperatures. $\triangle$ CAP at external environmental temperature $(\mathrm{ET}, \mathrm{n}=14) ; \triangle \mathrm{CAP}$ at room temperature $(\mathrm{RT}, \mathrm{n}=14)$; BBL Campy Pouches System (Cam.P) at ET $(n=16)$; Cam.P at RT $(n=16) ; \square$ CAS at ET $(n=16)$; CAS at RT $(n=16) ; n$, number of strains tested.

Table I. Survival of $H$. pylori on CAS with addition of $\mathrm{CO}_{2}$ at different temperatures

\begin{tabular}{|c|c|c|c|c|c|c|c|c|c|c|c|c|c|c|c|c|c|c|}
\hline \multirow{3}{*}{$\begin{array}{l}\text { Strain } \\
\text { no. }\end{array}$} & \multicolumn{18}{|c|}{ Grade of growth after storage for the following times (days )* } \\
\hline & \multicolumn{3}{|c|}{$1 / 8$} & \multicolumn{3}{|c|}{2} & \multicolumn{3}{|c|}{4} & \multicolumn{3}{|c|}{6} & \multicolumn{3}{|c|}{8} & \multicolumn{3}{|c|}{10} \\
\hline & ET & RT & $37^{\circ} \mathrm{C}$ & ET & RT & $37^{\circ} \mathrm{C}$ & ET & RT & $37^{\circ} \mathrm{C}$ & ET & RT & $37^{\circ} \mathrm{C}$ & ET & RT & $37^{\circ} \mathrm{C}$ & ET & RT & $37^{\circ} \mathrm{C}$ \\
\hline IRL911200 & +++ & +++ & +++ & +++ & +++ & +++ & +++ & +++ & +++ & - & + & ++ & - & - & - & - & - & - \\
\hline IRL911201 & +++ & +++ & +++ & +++ & +++ & +++ & + & ++ & +++ & + & + & $+t+$ & - & + & + & - & - & - \\
\hline IRL911206 & +++ & +++ & +++ & +++ & +++ & +++ & + & - & +++ & - & - & $+t+$ & - & - & - & - & - & - \\
\hline IRL911207 & +++ & +++ & +++ & +++ & +++ & +++ & +++ & + & ++ & + & + & + & + & - & + & - & - & - \\
\hline
\end{tabular}

ET, external environmental temperature; RT, room temperature.

${ }^{*}$ Grade of growth according to the number of colonies on subcultures (CAP): +++ , abundant; ++ , less, but uncountable;,$+<300$; - , no growth.

Table II. Survival of $H$. pylori on CAS without addition of $\mathrm{CO}_{2}$ at different temperatures

\begin{tabular}{|c|c|c|c|c|c|c|c|c|c|c|c|c|c|c|c|c|c|c|}
\hline \multirow{3}{*}{$\begin{array}{l}\text { Strain } \\
\text { no. }\end{array}$} & \multicolumn{18}{|c|}{ Grade of growth after storage for the following times (days )* } \\
\hline & \multicolumn{3}{|c|}{$1 / 8$} & \multicolumn{3}{|c|}{2} & \multicolumn{3}{|c|}{4} & \multicolumn{3}{|c|}{6} & \multicolumn{3}{|c|}{8} & \multicolumn{3}{|c|}{10} \\
\hline & ET & RT & $37^{\circ} \mathrm{C}$ & ET & RT & $37^{\circ} \mathrm{C}$ & ET & RT & $37^{\circ} \mathrm{C}$ & ET & RT & $37^{\circ} \mathrm{C}$ & ET & $\mathrm{RT}$ & $37^{\circ} \mathrm{C}$ & ET & RT & $37^{\circ} \mathrm{C}$ \\
\hline IRL911200 & ++ & ++ & +++ & +++ & +++ & +++ & + & + & +++ & + & - & + & + & - & + & - & - & - \\
\hline IRL911201 & +++ & +++ & +++ & +++ & +++ & +++ & + & + & + & + & - & $++t$ & - & - & + & - & - & - \\
\hline IRL911206 & +++ & +++ & +++ & +++ & +++ & +++ & - & - & + & - & - & - & - & - & - & - & - & - \\
\hline IRL911207 & +++ & +++ & +++ & +++ & +++ & +++ & + & + & ++ & + & + & ++ & + & + & - & - & - & - \\
\hline
\end{tabular}

*See footnote to table I. 


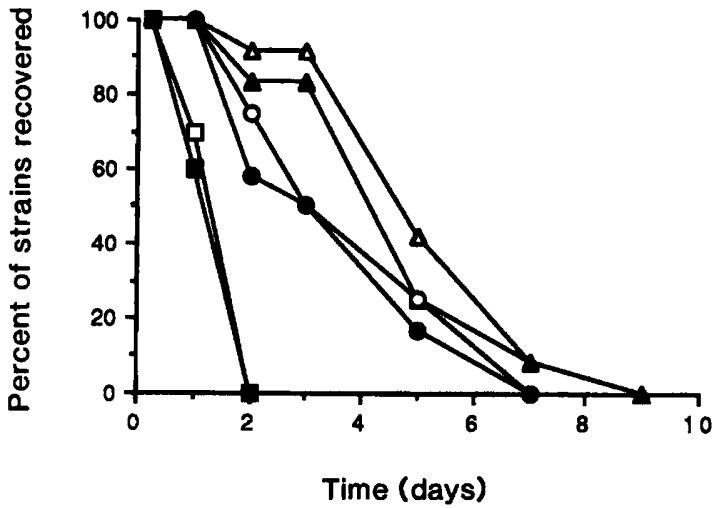

Fig. 2. Recovery rates of $H$. pylori after storage in liquid media at different temperatures. $\triangle$ BHIS at external environmental temperature (ET, $\mathrm{n}=12)$; $\triangle$ BHIS at room temperature $(\mathrm{RT}, \mathrm{n}=12)$; $\mathrm{NB}$ at ET $(\mathrm{n}=12)$; $\mathrm{NB}$ at RT $(\mathrm{n}=12) ; \square$ TSGS at ET $(\mathrm{n}=10)$; TSGS at RT $(\mathrm{n}=10) ; \mathrm{n}$, number of strains tested.

up to 8 days at $37^{\circ} \mathrm{C}$. Incubation with $\mathrm{CO}_{2}$ or exposure to air did not significantly influence recovery rate. The recovery rates at $37^{\circ} \mathrm{C}$ seemed to be higher than those at external temperature or room temperature (tables I and II).

\section{Evaluation of liquid transport media}

The survival time of $H$. pylori in BHIS was longer than in the other two liquid media tested. The recovery rate varied between 80 and $90 \%$ after storage for 3 days in BHIS, $50 \%$ in NB and zero in TSGS (fig. 2). The recovery rate of $H$. pylori after storage at external temperature $\left(-4^{\circ} \mathrm{C}\right.$ to $\left.14^{\circ} \mathrm{C}\right)$ was higher than that at room temperature $\left(21^{\circ} \mathrm{C}\right)$ in all media (figs. 1 and 2$)$.

\section{Discussion}

The availability of a suitable transport medium would greatly facilitate the transport of $H$. pylori cultures to different laboratories for study. However, no suitable transport system has been developed so far. In the present study, brain-heart infusion with horse serum $10 \%$ maintained viability of most $H$. pylori strains for longer than 3 days at temperatures from $-4^{\circ} \mathrm{C}$ to $21^{\circ} \mathrm{C}$, which shows that this medium would be suitable for transporting or mailing $H$. pylori strains. Only half of the strains in this study survived for 3 days at ambient temperatures in nutrient broth, which is used frequently to transport gastric biopsy specimens for isolation of $H$. pylori. Addition of horse serum may increase the recovery rate. Tryptone soya broth with glycerol $30 \%$ and horse serum $10 \%$ has been used as a storage medium in our laboratory and maintains the viability of $H$. pylori for $>18$ months at $-70^{\circ} \mathrm{C}$ (unpublished observation). None of the strains in this study survived in this medium at $-4^{\circ} \mathrm{C}$ to $21^{\circ} \mathrm{C}$ for $>1$ day.

However, broths are easily contaminated and less convenient to use than solid media. Most $H$. pylori strains did not survive on CAP after storage for 1 day at $-4^{\circ} \mathrm{C}$ to $21^{\circ} \mathrm{C}$. However, CAS maintained viability of all the $H$. pylori strains for 3 days and some strains for 9 days. The BBL Campy Pouch system also allowed a high recovery rate of $H$. pylori strains from CAP, but the expense and cumbersome nature of the system detracted from its value.

$\mathrm{CO}_{2}$ is essential for the isolation of $H$. pylori from gastric biopsy specimens. However, once isolated, most strains were capable of growth in an atmosphere with high humidity but without the addition of $\mathrm{CO}_{2}$ (unpublished observation). In the present study, the addition of $\mathrm{CO}_{2}$ had little effect on the recovery rate of $H$. pylori, which suggests that $\mathrm{CO}_{2}$ is not important for the maintenance of viable $H$. pylor $i$ in transport media.

Temperature can influence the recovery rate of $H$. pylori $^{2}$ In the present study, a higher recovery rate was achieved when the cultures were stored at $-4^{\circ} \mathrm{C}$ to $14^{\circ} \mathrm{C}$ than that at $21^{\circ} \mathrm{C}$. For CAS, storage at $37^{\circ} \mathrm{C}$ with or without the addition of $\mathrm{CO}_{2}$ prolonged the survival time of $H$. pylori. However, CAS at ambient temperature is a convenient medium for the effective transport of $H$. pylori.

Thus, although brain heart infusion with horse serum $10 \%$, the BBL Campy Pouch and CAS can maintain survival of most $H$. pylori strains for longer than 3 days at ambient temperature, we consider CAS with or without the addition of $\mathrm{CO}_{2}$ to be the most suitable transport system at present.

We thank Mr L. English and Dr F. Falkiner of the Department of Clinical Microbiology, St James's Hospital, Dublin, for their technical advice and for reading the manuscript.

\section{References}

1. Marshall BJ. Unidentified curved bacilli on gastric epithelium in active chronic gastritis. Lancet $1983 ; 1: 1273-1275$.

2. Goodwin CS, Blincow ED, Warren JR, Waters TE, Sanderson CR, Easton L. Evaluation of cultural techniques for isolating Campylobacter pyloridis from endoscopic biopsies of gastric mucosa. J Clin Pathol 1985; 38: 1127-1131.

3. Buck GE, Smith JS. Medium supplement for growth of Campylobacter pyloridis. J Clin Microbiol 1987; 25: 597-599.

4. Ansorg R, Recklinghausen GV, Pomarius R, Schmid EN.

Evaluation of techniques for isolation, subcultivation, and preservation of Helicobacter pylori. J Clin Microbiol 1991; 29: $51-53$.

5. Mathai E, Cafferkey M, Keane C, O'Morain C. Evaluation of different solid media used for cultivation of Helicobacter (Campylobacter) pylori. Indian J Med 1992; 95: 23-25.

6. Morgan DR, Freedman R, Depew CE, Kraft WG. Growth of Campylobacter pylori in liquid media. J Clin Microbiol 1987; 25 : 2123-2125.

7. Drumm B, Sherman P. Long-term storage of Campylobacter pylori. J Clin Microbiol 1989; 27: 1655-1656. 
8. Shahamat M, Mai UEH, Paszko-Kolva C, Yamamoto $H$, Colwell RR. Evaluation of liquid media for growth of Helicobacter pylori. J Clin Microbiol 1991; 29: 2835-2837.

9. Humphreys H, Bourke S, Dooley C et al. Effect of treatment on Campylobacter pylori in peptic ulcer disease: a randomised prospective trial. Gut 1988; 29: 279-283.

10. Queiroz DMM, Mendes EN, Rocha GA. Indicator medium for isolation of Campylobacter pylori. J Clin Microbiol 1987; 25: 2378-2379.
11. Megraud F, Bonnet F, Garnier M, Lamouliatte $H$ Characterization of "Campylobacter pyloridis" by culture, enzymatic profile, and protein content. J Clin Microbiol 1985; 22: 1007-1010.

12. Soltesz V, Zeeberg B, Wadström T. Optimal survival of Helicobacter pylori under various transport conditions. $J$ Clin Microbiol 1992; 30: 1453-1456.

13. Owen RJ, On SLW, Costas M. Potential transport medium for Campylobacter pylori. J Clin Pathol 1988; 41 : 1337-1338. 